\title{
The Barriers of Local E-Government in China-A Case Study
}

\author{
Lemei Liu \\ Department of Political Science and Law, Yu Lin University ,Yu Lin City, Shaanxi Province, P. R.
China
} 190242971@qq.com

Keywords: E- Government; Barriers; Local government; Technology

\begin{abstract}
Over the past few years, e-government has become increasingly popular around the world. The e-government develops in the context of significant economical, political, technological and social changes. What are the challenges and barriers that hinder the e-government development? Overall, there are a number of barriers which degrade successful implementation of e-government and thus prevent the realisation of anticipated benefits. These factors can be organized into political, economical, technological, administrative, organisational, institutional and socio-cultural obstacles.

In this study, the purposive sampling method and the semi-structured interviews are used to collect information about the factors may hinder the faster progress towards e-government. In the case of the studied local government $X$, There are several factors mentioned by interviewees that serve to constrain the development of e-government. These barriers include: (1) too big vision but lack of guidance; (2) the lack of awareness/insufficient attention; (3) technical obstacles, and (4) cultural obstacles. The technology was merely seen as a tool rather than a new opportunity to transform the government. The concept of e-government has generated no more than some surface change. Overall, the e-readiness in an area should be taken into account when the government intends to develop e-government strategies. More importantly, the adoption of e-government in the public sector will not automatically create a better government, and the successful implementation is based on efforts to promote the utilization of technologies.
\end{abstract}

\section{Introduction}

Since the 1990s, the concept of 'e-government' has increasingly attracted attention either from scholars or from government officials. Actually, with regard to e-government, there does not exist a universally accepted definition of this concept. However, there are still certain similar features exist amongst these definitions, i.e. the pursuit of better government including (1) more efficient government; (2) better delivery of public services to citizens, and (3) improved democratic processes. This study adopts the term 'e-government' in this sense, i.e. all use of information technology in the public organizations aimed at better government.

Generally speaking, the e-government develops in the context of significant economical, political, technological and social changes. Modern technologies are regarded as useful instruments by many private companies to better serve the needs of customers for survival. As more and more people experience the benefits brought by the Internet and web-based technologies in the private sector, there is a growing expectation that the public sector could provide the same level of service which is comparable to that of private companies.

In practice, the Chinese government has launched a series of government online projects, including the 'Golden Card', 'Golden Bridge', 'Government Online', 'Family Online', and etc. Scholars have done some studies on these e-government projects [1]argues that, most of the research of e-government by Chinese scholars focuses on how to use western advanced theories to analyse the Chinese cases, rather than studying the Chinese e-government itself, let alone the specialized analysis of local e-government. This is one reason as to why the researcher choses to study the Chinese local e-government. Another reason is that there are quite few studies on the e-government initiatives in the developing countries, thus the study of Chinese e-government case could provide knowledge for exploring the situation in less developed areas, which is helpful for other researchers to conduct further studies. 


\section{Methodology}

Sampling. In this study, the selection of participants is purposive. Purposive/judgment sampling is precisely the term suggests, i.e. members of a sample are selected with a purpose, based on the researcher's own knowledge, to represent the population[2]. In this study, the participants were chosen because they are involving the e-government implementation process which will enable the researcher to do detailed exploration of the central theme which the study wishes to study.

Contacts with the potential participants were established firstly with several international phone calls. For this research, informed consents were easily obtained from all the participants, since I have done an internship in the local government and all the staff there are quite familiar, as noted earlier. In addition, I know the organisational framework within the local government, which is helpful to decide which potential participants should be selected. In the end, the sample consisted of 8 people. One is the leader of the local government. One is the deputy leader of the government, who is in charge of the e-government project. Another is the technical official that is responsible for all the technical problems related to e-government projects. The other 5 individuals are ordinary government employees working in different departments. For convenience sake, all the respondents were coded in the study (see Table 1):

Table 1 Samples

\begin{tabular}{|c|l|c|l|}
\hline Interviewees & \multicolumn{1}{|c|}{ Occupation } & Interviewees & \multicolumn{1}{c|}{ Occupation } \\
\hline P1 & $\begin{array}{l}\text { An employee in the } \\
\text { financial } \\
\text { department }\end{array}$ & P5 & $\begin{array}{l}\text { A government } \\
\text { statistician }\end{array}$ \\
\hline P2 & $\begin{array}{l}\text { An employee in the } \\
\text { civil affair } \\
\text { department }\end{array}$ & P6 & A technical official \\
P3 & $\begin{array}{l}\text { An employee in the } \\
\text { government service } \\
\text { centre }\end{array}$ & P7 & $\begin{array}{l}\text { The deputy leader, } \\
\text { who is in charge of } \\
\text { e-government }\end{array}$ \\
\hline P4 employee in the & P8 department & $\begin{array}{l}\text { The chief leader in } \\
\text { the local } \\
\text { government }\end{array}$ \\
\hline
\end{tabular}

Interview. In this study, semi-structured interviews were adopted to collect information. In the semi-structured in-depth interview, a limited number of topic guide questions were prepared in advance but the interviewees were not provided with specific answer categories; rather, the prepared open ended questions were asked, which allows the interviewee to respond any way he/she prefers [3]. The interviews were undertaken in July 2017 (4-10 July). A total number of 8 interviews were interviewed separately, by a face-to-face meeting, by myself in the participants' offices. The interviews lasted from 30 minutes to 1 hour and the length of the time varies, which is determined by the participants' responses.

\section{Barriers Delaying the Progress of Chinese Local E-Government}

There are several factors mentioned by interviewees that serve to constrain the development of e-government. These barriers include: (1) too big vision but lack of guidance; (2) the lack of awareness/insufficient attention; (3) technical obstacles, and (4) cultural obstacles.

Over-ambitious Goals and Lack of Guidance. The e-government development in China has some problems: the over-ambitious plans together with the lack of guidance, which had been agreed by all the respondents. Since 1993s, the Chinese central government has launched a series of government online projects, trying to 'leapfrog' western advanced countries like the United Kingdom and the United States. Following this thinking, the Chinese central government has issued a series of official documents with regard to how to marry the opportunities of ICTs with the 
country's unfinished industrialisation process. After receiving the directives from the higher level governments, local governments just need to work according to these directives. Why it is quite problematic is because usually the directive was set without sufficient prior investigation of the feasibility of the local e-government projects, as ascertained by the deputy leader in the government. The lack of field investigation results in a problem that is 'perhaps e-government projects does not fit the district currently but the local government just makes hasty decisions to adopt the e-government projects' (P7). In the case of the studied local government X, the decision to develop e-government was made mainly from the perspective of supply side, in order to obey the demand from the higher level or central government. However, according to P7, the local context such as low incomes, low education and poor infrastructure seems to have significantly hindered the e-government development.

Another hindrance is the lack of guidance. The central government just worked out a very general work plan for e-government development and set several targets like by which year what percentage of government services should be put online. However, as the chief leader stated that, 'We do not know what the specific objectives we are trying to achieve. For instance, if the objective is to buy some computers and fax machines, then we have already finished the process. However, according to many experts, we have not finished it. Thus, what are the real objectives? What should the standards be set? The official documents we have received so far just give very general instructions. Therefore, in order to successfully implement e-government, more specific and long-term instructions are needed. (P8)

Actually, Li [4] has argued that the lack of uniform standard in implementing e-government poses a real challenge to Chinese local governments. According to $\mathrm{Li}$, developing e-government initiatives and promoting informatization needs uniform programming standard. No such standard will delay the progress of government digitalization.

Lack of Awareness (or Insufficient Attention). The lack of awareness of the value of e-technologies is another barrier to the success of the local e-government projects. When the researcher asked the participants 'what do you understood by the term e-government?', all the interviewees gave the same answer (slightly different expressions but same meaning): the application of modern technologies such as computer, Internet, phone, fax and etc. in the government. From their understanding, e-government was in essence a tool for public servants. None of them mentioned other value of e-government, such as better service delivery and more customer oriented services and etc., which to some extent, reflects that they have not paid enough attention to the e-government projects. In addition, according to the ordinary government employees interviewed (P1, P2, P3 and P6), the leaders of most local governments had not realized the great potential of e-government to transform the traditional administration, thus 'they do not give the e-government enough priority' (P3). The technical official directly pointed out that 'the local government has enough money, but the leaders prefer not to invest in e-government projects since they think it is a kind of resource wasting' (P6). The chief leader provided another reason for this by arguing that computers were not very good at everything and always some level of human intervention were required. This argument to some extent reflects that the usefulness of ICTs has not crossed the minds of most Chinese bureaucrats. According to scholars such likeZhao [6]and Shalini [7], the shortage of attention from the leadership is among the challenges that hinders the government digitalization process. In the studied local government case $X$, the lack of attention of the e-government was regarded as the most important impediment for the e-government development by almost all the respondents. The employee in the financial department even ascertained that the e-government projects could achieve successes as long as the leadership of the government paid enough attention to it (P1). P2 was in the civil affair department, and suggested a similar viewpoint as well.

Technical Barriers. With regard to the technical barriers, four main points were mentioned by the interviewees: hardware, software, security issues, and the lack of technical staff. First, according to all the respondents, the insufficient infrastructure in the studied region is a barrier for the application of e-government. Actually, the lack of IT infrastructure has been regarded as an 
important obstacle which the e-government implementation faces. So far, although the radio and cable television coverage in China have reached $97.51 \%$ and $98.20 \%$ respectively, high costs still hugely prevent the majority of rural people (or peasants) from gaining access to the Internet, only with a $27.5 \%$ Internet penetration rate [8]. Apart from this, deficiencies in physical infrastructure also exist in the government. According to the technical official, the computers equipped with government employees were too old and it is quite usual that the computer crashed when they were dealing with things. He claimed that the poor infrastructure should be taken into consideration if the government had the desire to achieve successful implementation of e-government projects.

Second, the software issues also pose a challenge to the progress of e-government. In the software industry, United States-sourced software still claims a substantially larger market share. Particularly, when it comes to the desktop, operating system and office suite, Microsoft is absolutely a giant monopoly [9]. This leads to the third problem, i.e. security problems. The security issues have been seen as potential barriers that confront the successful implementation of e-government. In the studied government $\mathrm{X}$, both the technical official and the government statistician expressed their concerns about the security of personal information collected and shared by government departments. In China, currently either the capability in research or the development of information technology is relatively weak. So far, the structure of China's IT industry remains mainly reliant on United States-sourced CPUs. Partly for this reason, security measures used in the Chinese e-government projects are very weak and far from meeting even minimum requirements. As Li [10]states that, only safe technologies can guarantee the security of government information. Therefore, as long as China does not have its own reliable software, security issues will be always the greatest danger in developing e-government, as declared by the technical official (P6).

Additionally, as the deputy leader maintained, the shortage of qualified technical specialists also delays the e-government progress. The poor areas do not have sufficient well-trained technical personnel currently and it is quite doubtful that computer specialists who return from advanced areas will be willing to settle down in China's poor areas. Even though they may invest on developing technical staff, their training may not produce skilled technical staff in the short term, as noted by Ebrahim and Irani [5]. According to Weerakkody and Choudrie, the lack of IT staff is another hindrance that delays the faster progress of e-government. In the case of the local government $\mathrm{X}$, there is only one technical staff, whose major is not computer. In the words of the technical staff, 'I got this job because the government needed a technical staff at that time and I had gone on a computer training course before' (P6). The lack of computer expertise could result in real dangers. The employee in the service centre and the technical official directly pointed out that if something serious breaks, they do not have anybody who can fix it.

Cultural Barriers. Cultural resistance is perhaps the greatest impediment to digitalize government activities. Many employees in the local government have a natural tendency to cling to the old and familiar way and resist the intrusion of ICTs in their daily work (Particularly, in the first place, the majority of the respondents mentioned that the old age of employees impacted on the unwillingness to embrace new technologies, hence hampering the development of e-government. For example, the employee in the civil affair department stated that:'One reason for the slow development of e-government is that the majority of our employees are relatively old (many were born in 1950s and 1960s). On one hand, they do not want to spend much time learning about how to use a new technology. On the other hand, usually it will take time for mastering a new technology and they do not have enough energy for that.' (P2)

Therefore, the result is that in the local government, most of the government officials are incapable of using information technology, which delays the progress of China's e-government.

In addition, as the two government leaders claimed that, the traditional organisational structure and traditional idea of administrative officials are also obstacles to the development of e-government in the local government $\mathrm{X}$. The successful implementation of e-government projects requires the interconnection between different functionaries to deal with public affairs. However, according to Snellen and Thaens [11], the cooperation amongst government departments is really difficult because of the complexity of administrative structures and the lack of collaboration has 
been identified as an obstacle for the e-government development.

According to the two employees, who was in the service centre and in the tax department respectively, different government functionaries should have different access rights to information. 'If the information collected by one agency are entirely accessible to other agencies, then the agency will gradually lose its power' (P3). Here they were seemingly worried about the loss of the power of government departments, but essentially they were expressing their concern about the loss of their own power, though very obliquely. This view echoes the argument made by Ebrahim et al. [12], that is some public servants regard e-government as a potential threat to their power so they are unwilling to promote the government digitalization progress. Just as $\mathrm{Li}$ and Schwester state that, e-government challenges the traditional administrative power so some employees are against it. The employee in the tax department even provided an interesting example:"Before the introduction of e-government, public servants in a department usually feel they have power over the issues associated with their own department. When people come to them to deal with things, sometimes they may intentionally pose some obstacles to people. However, they will to a large extent lose this kind of power. This also explains why government officials do not want to introduce e-government.' (P4)

The chief leader (P8) and the deputy leader (P7) also mentioned a potential danger associated with corruption issues. Transparency is regarded as a significant value of e-government projects and the implementation of e-government means putting loads of relevant information online, which allows ordinary people to check what is going on in the government.

Apart from the barriers arising from government, user culture in the studied area also hampers the e-government development. The interviewees emphasized several main points with regard to users barriers. First, according to the deputy leader, there are not many people who both afford to access to the Internet and are capable of using it in the studied area, hence to some extent, it is fair to claim that e-government is not so desperately needed here. In China, issues relating to the digital divide are severe. Most Internet users are located in comparatively wealthy cities like Beijing, Shanghai or Guangzhou. As mentioned earlier, the Internet penetration rate in rural China is only $27.5 \%$ [13]. In the relatively poor area, many of people do not have the skills to use electronic services.

In summary, various barriers were mentioned by the eight respondents, which reflect their own understanding about the e-government based on their own knowledge and the local context. However, unlike the discussion in the dominant literature, none of the interviewees mentioned the economic and financial constraints. As discussed in the literature review, economical constraints have been regarded as important impediments with regard to the development of e-government by many studies. Based on this knowledge, after finishing each interview, the researcher asked the interviewee whether he/she had economical pressure and all the answer were no. According to P3, who was in the service centre, the government has enough funds and whether to use them to develop e-government mainly depends on the leaders' decisions. The chief leader also explained that they thought financial resources are not problems, because they could usually receive enough funds allocated by higher level governments.

\section{Conclusions}

Since 1990s, the Chinese government leadership has been aware of the value of modern technologies and tried to marry the opportunities of the information technology revolution with the unfinished industrialisation process. This attempt leads to a series of initiatives such like 'Government Online' and 'Family Online' launched in China, from the central government to local governments. Thus the demand from the higher level governments were regarded as the most important determinant to implement e-government. As to the barriers to e-government, over-ambitious goals, the lack of guidance, insufficient attention, technological barriers, and cultural barriers were mentioned by the interviewees. The Chinese central government tends to set very ambitious goals but just creates very general instructions for local governments to follow. In the case of e-government development, initially, the Chinese central government attempts to 
introduce new technologies to 'leapfrog' the western industrialized countries, but there is no specific guidance. In additional, the lack of awareness of the value of ICTs the leaders of local government $\mathrm{X}$, and technological issues, both have hindered the faster progress towards e-government. Last but not the least, cultural barriers also matter a lot. On the one hand, public servants are reluctant to embrace the idea of e-government. On the other hand, the citizens are incapable of using electronic services. Overall, the low level of e-readiness in the studied region contributes to the failure of e-government.

Overall, the e-readiness in an area should be taken into account when the government intends to develop e-government strategies. More importantly, according to Asgarkhani [14], the adoption of e-government in the public sector will not automatically create a better government, and the successful implementation is based on efforts to promote the utilization of technologies.

\section{References}

[1] Cai, L. H., 2009. E-Government. Beijing: Tsing Hua University Press.

[2] Berg, B. L. and Lune, H., 2016. Qualitative Research Methods for the Social Sciences. 8th ed. Essex: Pearson Education Limited.

[3] Rubin, H. and Rubin, I., 2015. Qualitative Interviewing: The Art of Hearing Data. 3rd, ed. London: Sage Publications Ltd.

[4] Li, B. L., 2005. On the Barriers to the Development of E-Government in China. In: ICEC, 7th International Conference on Electronic Commerce. New York, USA, 2005. New York: ACM.

[5] Ebrahim, Z. and Irani, Z., 2015. E-Government Adoption: Architecture and Barriers. Business Process Management Journal, 11 (5), pp. 589-611.

[6] Zhao, G. J., 2016. Electronic Government. 2nd, ed. Beijing: Publishing House of Electronics Industry.

[7] Shalini, R., 2009. Are Mauritians Ready for E-government Services" Government Information Quarterly, 26 (3), pp. 536-539.

[8] China Internet Network Information Center (CNNIC), 2014. The 33th Survey Report on Internet Development in Rural China. [online] Available at: < http://www.cnnic.net.cn/hlwfzyj/hlwxzbg/ncbg/201406/P020140611558782533389.pdf>[Acces sed 17 July 2014].

[9] China Software Industry Association (CSIA), 2013. 2013 Report on China Software Industry Development. [online]Available at: < http://wenku.baidu.com/view/cc4d8dda050876323012120a.html > [Accessed 17 July 2014].

[10] Li, B. L., 2005. On the Barriers to the Development of E-Government in China. In: ICEC, 7th International Conference on Electronic Commerce. New York, USA, 2005. New York: ACM.

[11] Snellen, I. and Thaens, M., 2008. From E-Government to M-Government: Towards a New Paradigm in Public Administration? In: Formez, 2008. Innovazione Amministrativa E Crescita, Rapporto conraccomandazioni, Volume VIII International Comparisons, Ricera Giannini-Formez II fase, Roma, pp. 211-253.

[12] Ebrahim, Z. and Irani, Z., 2005. E-Government Adoption: Architecture and Barriers. Business Process Management Journal, 11 (5), pp. 589-611.

[13]China Internet Network Information Center (CNNIC), 2014. The 33th Survey Report on Internet Development in Rural China.

[14]Asgarkhani M., 2016. Digital Government and Its Effectiveness in Public Management Reform: A Local Government Perspective. Public Management Review, 7 (3), pp. 465-487. 